Editorial

\title{
Recent Advances in Mechanics of Non-Newtonian Fluids
}

\author{
Wei-Tao $\mathrm{Wu}^{1}$ and Mehrdad Massoudi ${ }^{2, * \mathbb{D}}$ \\ 1 School of Mechanical Engineering, Nanjing University of Science \& Technology, Nanjing 210094, China; \\ weitaowwtw@njust.edu.cn \\ 2 U. S. Department of Energy, National Energy Technology Laboratory (NETL), Pittsburgh, PA 15236, USA \\ * Correspondence: mehrdad.massoudi@netl.doe.gov
}

Received: 2 January 2020; Accepted: 5 January 2020; Published: 8 January 2020

Keywords: lubrication; suspensions; viscoplastic fluids; cement; biofluids; oil recovery; porous media

Flow of non-Newtonian (non-linear) fluids occurs not only in nature, for example, mud slides and avalanches, but also in many industrial processes involving chemicals (polymers), biological materials (blood), food (honey, ketchup, yogurt), pharmaceutical and personal care items (shampoo, creams), etc. In general, these fluids exhibit certain distinct features such as shear-rate dependency of the viscosity (related to shear-thinning or shear-thickening aspects of the fluid), normal stress effects (related to die-swell and rod-climbing), creep or relaxation (viscoelasticity), yield stress effects (viscoplasticity), history effects (time dependent response), etc. There are many different models which can be used for different fluids under different conditions. For excellent overall discussion of these fluids, see Barnes, et al. [1], Larson [2], Tanner [3], Schowalter [4], Carreau, et al. [5], Macosko [6], and Bird, et al. [7]; for a more mathematical approach, see Deville and Gatski [8], Coleman, et al. [9], and Huilgol and Phan-Thien [10]; for a computational approach, see Crochet, et al. [11] and Owen and Phillips [12]; for a historical perspective, see Tanner and Walters [13]; and for a general introduction to measurement techniques, etc., see Coussot [14] and Walters [15].

This special issue of Fluids is dedicated to recent advances in the mathematical and physical modeling of non-linear fluids, with specific applications in lubrication, suspensions, viscoplastic fluids, cement, biofluids, oil recovery, porous media, and relevant numerical issues.

Formulating and solving flows of inhomogeneous fluids presents special difficulties, especially in the mathematical and numerical scheme. Fusi, et al. [16] consider the pressure-driven thin film flow of fluids whose viscosity depends on the density of the fluid. They use a thermodynamical framework to obtain the constitutive relation for the fluid, and by assuming a small aspect ratio for the channel, they use the lubrication approximation. The non-linear equations are solved numerically and the evolutions of the density in the fluid are plotted.

Hamedi and Westerberg [17] look at the two-dimensional flow of a Bingham fluid and its interactions with side-by-side cylinders. They study this problem numerically using the Open Source CFD Code OpenFOAM and discuss the influence of the gap between the cylinders on the drag force and the shape of the unyielded regions. Their results are presented for various Reynolds and Bingham numbers.

Rees and Bassom [18] study the free convection flow of a non-Newtonian fluid modeled as a Bingham fluid in a vertical porous channel. The heat is supplied both at the sidewalls and through an internal source of heat generation. Their results indicate that four different flow regimes arise: (1), one corresponding to complete stagnation, (2) one having one stagnation region, (3) and (4) two more regions with two stagnant regions. The authors also discuss how the locations of the yield surfaces evolve depending on the values of the Darcy-Rayleigh and Rees-Bingham numbers. 
Pereira, et al. [19] rigorously derive the Reynolds lubrication approximation for steady flows of incompressible non-Newtonian fluids with shear dependent viscosity. They use a perturbation analysis and show that depending on the power-law character of the fluid, the derived equations can either be prescribed as a higher-order correction to the Reynolds equation or a new type of Reynolds equation for these non-linear fluids. They present the results for two flow conditions: flow in an eccentric journal bearing and flow between a rolling rigid cylinder and a plane.

Jabbari, et al. [20] use a first-order projection method to numerically solve the unsteady flow of (1) an incompressible Navier-Stokes fluid inside a three-dimensional lid-driven cavity, and (2) a power-law non-Newtonian fluid, for different cavity aspect ratio, and for three different Reynolds numbers, namely 100, 400, and 1000. They notice that as the power-law exponent $n$ decreases (the fluid being more shear-thinning) the secondary flows become less pronounced.

Seeking and obtaining exact solutions for flows of fluids under different flow conditions and geometries is a great challenge to mathematicians and engineers. Mahabaleshwar, et al. [21] obtain an exact solution for the flow of a fluid through a semi-infinite porous medium with a slip boundary condition (using Navier's approach). They present their results considering the effects of slip parameters, the mass transpiration parameter, the Brinkman ratio, and the impact of shearing.

Ribau, et al. [22] study the Poiseuille-Couette flow of a viscoelastic fluid when the fluid is represented by a recently proposed model, generalizing the Phan-Thien-Tanner (PTT) constitutive equation. The new model has one or two new fitting parameters which can be used to fit the experimental data for a wider ranging application. The authors present their results for the velocity profiles for various parameters, including the new parameters in the generalized PTT model.

Baranovskii, et al. [23] study the non-linear equations describing the steady non-isothermal creeping flows of an incompressible viscous fluid and establish the existence of weak solutions. In their formulation, they assume that viscosity and thermal conductivity coefficients depend on the temperature; they also use mixed boundary conditions.

Farsaci, et al. [24] develop a thermodynamic model of hemoglobin; their model is based on experimental data and the physical point of view favoring the binding of oxygen to the protein. Their model, using non-equilibrium thermodynamics, introduces a phenomenological coefficient related to the displacement polarization current.

Asadi, et al. [25] numerically study the rupture of a membrane located between two fluids. They use the smoothed particle hydrodynamics (SPH) and the finite element method (FEM) to solve the problem and consider a range of pressure difference and membrane thicknesses. For the fluid phase, they use the Lagrangian form of the Navier-Stokes equations; these equations are coupled to the solid phase equations which use the von Mises elastic-plastic criterion.

Rosenbaum, et al. [26] study the influence of bubbles on the shear viscosity of foamed cement; the cement slurry is modeled as a fluid suspension and in their numerical simulations, they use an extended version of Stokesian Dynamics along with Fast Lubrication Dynamics. Bubbles are introduced/injected into the cement slurry to reduce the density, increase the viscosity, and improve the properties of cement. The simulated results for the viscosity show close agreement with traditional viscosity correlations for suspensions.

Baba, et al. [27] study the mixture flow of gases and liquids in pipelines; slug flow pattern has been shown to be the dominant flow regime for very viscous oils which are used in chemical and petroleum industries. They consider the impact of air and mineral oils, along with the influence of high liquid viscosity on the slug velocity; the authors propose a new empirical correlation for the slug velocity for highly viscous two-phase flows.

Viscoelastic surfactants such as Wormlike Micellar Solutions (WMS) have certain positive characteristics which can be used to overcome some of the difficulties encountered in chemical enhanced oil recovery (CEOR) techniques. Jafari Nodoushan, et al. [28] review the major approaches and challenges encountered in using these chemical agents. They indicate that the shear-thinning 
property of WMS along with their breakage under high shear stresses can lead to a better injectivity and trapping of oil in low-permeability zones.

The buoyancy driven flow (natural convection) of a suspension composed of rigid particles and a fluid between two vertical walls is studied by Tao, et al. [29]. They model the suspension as a nonlinear fluid with a viscosity which depends on the shear rate and the particle concentration. To consider the motion of the particles, they use a convection-diffusion equation and perform a parametric study (after having non-dimensionalized the equations). They present their results for concentration, velocity, and temperature profiles in terms of various dimensionless numbers.

Acknowledgments: Finally, we would like to thank all the authors who contributed to this special issue. We are also grateful to all the anonymous reviewers for their help; without the help of qualified reviewers, it would not have been possible to organize this special issue. A personal note of appreciation and gratitude to Sonia Guan, the Managing Editor of Fluids, and the editorial staff at the Fluids Office; without their help and assistance, Fluids could not publish high quality papers in a short period of time.

Conflicts of Interest: The authors declare no conflict of interest.

\section{References}

1. Barnes, H.A.; Hutton, J.F.; Walters, K. An Introduction to Rheology; Elsevier: Amsterdam, The Netherlands, 1989; Volume 3.

2. Larson, R.G. The Structure and Rheology of Complex Fluids; Oxford University Press: New York, NY, USA, 1999; Volume 150.

3. Tanner, R.I. Engineering Rheology, 2nd ed.; Oxford University Press: Oxford, UK, 2000; Volume 52.

4. Schowalter, W.R. Mechanics of Non-Newtonian Fluids; Pergamon Press: Oxford, UK, 1978.

5. Carreau, P.J.; De Kee, D.C.R.; Chhabra, R.P. Rheology of Polymeric Systems: Principles and Applications Hanser; American Institute of Chemical Engineers: New York, NY, USA, 1997.

6. Macosko, C. Rheology: Principles, Measurements and Applications; Wiley-VCH Inc.: New York, NY, USA, 1994.

7. Bird, R.B.; Armstrong, R.C.; Hassager, O. Dynamics of Polymeric Liquids. Volume 1: Fluid Mechanics, 2nd ed.; Wiley: Hoboken, NJ, USA, 1987.

8. Deville, M.; Gatski, T.B. Mathematical Modeling for Complex Fluids and Flows; Springer Science \& Business Media: Berlin/Heidelberg, Germany, 2012.

9. Coleman, B.D.; Markovitz, H.; Noll, W.; Markovitz, H.; Noll, W. Viscometric Flows of Non-Newtonian Fluids: Theory and Experiment; Cambridge University Press: Cambridge, UK, 1966; Volume 5.

10. Huilgol, R.R.; Phan-Thien, N. Fluid Mechanics of Viscoelasticity: General Principles, Constitutive Modelling, Analytical and Numerical Techniques; Elsevier: Amsterdam, The Netherlands, 1997; Volume 6.

11. Crochet, M.J.; Davies, A.R.; Walters, K. Numerical Simulation of Non-Newtonian Flow; Elsevier: Amsterdam, The Netherlands, 2012; Volume 1.

12. Owens, R.G.; Phillips, T.N. Computational Rheology; World Scientific: Singapore, 2002; Volume 14.

13. Tanner, R.I.; Walters, K. Rheology: An Historical Perspective; Elsevier: Amsterdam, The Netherlands, 1998; Volume 7.

14. Coussot, P. Rheometry of Pastes, Suspensions, and Granular Materials: Applications in Industry and Environment; John Wiley \& Sons: Hoboken, NJ, USA, 2005.

15. Walters, K. Rheometry, Industrial Applications; Wiley: Hoboken, NJ, USA, 1980; Volume 1.

16. Fusi, L.; Farina, A.; Rosso, F.; Rajagopal, K. Thin-Film Flow of an Inhomogeneous Fluid with Density-Dependent Viscosity. Fluids 2019, 4, 30. [CrossRef]

17. Hamedi, N.; Westerberg, L.-G. On the Interaction of Side-By-Side Circular Cylinders in Viscoplastic Fluids. Fluids 2019, 4, 93. [CrossRef]

18. Rees, D.A.S.; Bassom, A.P. The effect of internal and external heating on the free convective flow of a Bingham fluid in a vertical porous channel. Fluids 2019, 4, 95. [CrossRef]

19. Pereira, B.M.M.; Dias, G.A.S.; Cal, F.S.; Rajagopal, K.R.; Videman, J.H. Lubrication Approximation for Fluids with Shear-Dependent Viscosity. Fluids 2019, 4, 98. [CrossRef]

20. Jabbari, M.; McDonough, J.; Mitsoulis, E.; Hattel, J.H. Application of a projection method for simulating flow of a shear-thinning fluid. Fluids 2019, 4, 124. [CrossRef] 
21. Mahabaleshwar, U.S.; Vinay Kumar, P.N.; Nagaraju, K.R.; Bognár, G.; Nayakar, S.N. A New Exact Solution for the Flow of a Fluid through Porous Media for a Variety of Boundary Conditions. Fluids 2019, 4, 125. [CrossRef]

22. Ribau, Â.M.; Ferrás, L.L.; Morgado, M.L.; Rebelo, M.; Afonso, A.M. Semi-Analytical Solutions for the Poiseuille-Couette Flow of a Generalised Phan-Thien-Tanner Fluid. Fluids 2019, 4, 129. [CrossRef]

23. Baranovskii, E.S.; Domnich, A.A.; Artemov, M.A. Optimal Boundary Control of Non-Isothermal Viscous Fluid Flow. Fluids 2019, 4, 133. [CrossRef]

24. Farsaci, F.; Tellone, E.; Galtieri, A.; Ficarra, S. A New Model for Thermodynamic Characterization of Hemoglobin. Fluids 2019, 4, 135. [CrossRef]

25. Asadi, H.; Taeibi-Rahni, M.; Akbarzadeh, A.M.; Javadi, K.; Ahmadi, G. Investigation of Hydrodynamically Dominated Membrane Rupture, Using Smoothed Particle Hydrodynamics-Finite Element Method. Fluids 2019, 4, 149. [CrossRef]

26. Rosenbaum, E.; Massoudi, M.; Dayal, K. The Influence of Bubbles on Foamed Cement Viscosity Using an Extended Stokesian Dynamics Approach. Fluids 2019, 4, 166. [CrossRef]

27. Baba, Y.D.; Archibong-Eso, A.; Aliyu, A.M.; Fajemidupe, O.T.; Ribeiro, J.X.F.; Lao, L.; Yeung, H. Slug translational velocity for highly viscous oil and gas flows in horizontal pipes. Fluids 2019, 4, 170. [CrossRef]

28. Jafari Nodoushan, E.; Yi, T.; Lee, Y.J.; Kim, N. Wormlike Micellar Solutions, Beyond the Chemical Enhanced Oil Recovery Restrictions. Fluids 2019, 4, 173. [CrossRef]

29. Tao, C.; Wu, W.-T.; Massoudi, M. Natural Convection in a Non-Newtonian Fluid: Effects of Particle Concentration. Fluids 2019, 4, 192. [CrossRef]

(C) 2020 by the authors. Licensee MDPI, Basel, Switzerland. This article is an open access article distributed under the terms and conditions of the Creative Commons Attribution (CC BY) license (http://creativecommons.org/licenses/by/4.0/). 